\title{
Solid State NMR for Nonexperts: An Overview of Simple but General Practical Methods
}

\author{
Ilya G. Shenderovich ${ }^{1, *(1)}$ and Hans-Heinrich Limbach ${ }^{2}$ \\ 1 Institute of Organic Chemistry, University of Regensburg, 93053 Regensburg, Germany \\ 2 Institut für Chemie und Biochemie, Freie Universitat Berlin, 14195 Berlin, Germany; \\ limbach@chemie.fu-berlin.de \\ * Correspondence: Ilya.Shenderovich@ur.de; Tel.: +49-94-1943-4027
}

Citation: Shenderovich, I.G.;

Limbach, H.-H. Solid State NMR for Nonexperts: An Overview of Simple but General Practical Methods. Solids 2021, 2, 139-154. https://doi.org/ $10.3390 /$ solids2020009

Academic Editor: Guido Kickelbick

Received: 9 March 2021

Accepted: 30 March 2021

Published: 1 April 2021

Publisher's Note: MDPI stays neutral with regard to jurisdictional claims in published maps and institutional affiliations.

Copyright: (c) 2021 by the authors. Licensee MDPI, Basel, Switzerland. This article is an open access article distributed under the terms and conditions of the Creative Commons Attribution (CC BY) license (https:/ / creativecommons.org/licenses/by/ $4.0 /)$.

\begin{abstract}
There are varieties of methods available for the exploration of solids using nuclear magnetic resonance (NMR) spectroscopy. Some of these methods are quite sophisticated, others require specialized equipment. This review is addressed to those for whom NMR is not the main research method. It discusses simple methods that can be applied to solids with little or no adaptation to a specific system. Despite their technical simplicity and ease of use, these methods are powerful analytical tools that provide unique insights into the structure, dynamics, and noncovalent interactions in homo- and heterogeneous systems. Particular attention is paid to the characterization of porous materials and solids containing phosphorus. ${ }^{31} \mathrm{P}$ NMR of organometallic compounds has been used as an example of how theoretical calculations can help in deeper analysis of experimental data.
\end{abstract}

Keywords: ${ }^{1} \mathrm{H}$ NMR; ${ }^{13} \mathrm{C}$ NMR; ${ }^{15} \mathrm{~N}$ NMR; ${ }^{29} \mathrm{Si}$ NMR; ${ }^{31} \mathrm{P}$ NMR; mesoporous silica; organometallic complexes; surface; hydrogen bonding; DFT

\section{Introduction}

Science is becoming more and more interdisciplinary [1]. This happens at all scales. Almost all experimental studies use more than one method to characterize the object under study. Even when each particular method is supervised by an expert in the field, the principal investigator should be able to formulate the questions that each method should answer. Commonly used methods do not cause this problem. One of such universal methods is solution-state nuclear magnetic resonance (NMR) when used for structure elucidation in chemistry. In most cases, a given structure can be determined using the usual set of standard methods familiar to every synthetic chemist. On the contrary, when this method is used to study noncovalent interactions, the set of required NMR techniques must be expanded and adapted to the particular system under consideration. Many of these techniques are easy to implement as well. When done correctly, NMR can provide truly unique information [2-5]. The same is with solid state NMR. Much can be gained by asking clearly. The studied system can be crystalline, amorphous, porous, polymeric, or heterogeneous. The main thing is to find NMR-active nuclei, whose parameters depend on the property that needs to be studied. A deeper understanding of the systems under study can be achieved by calculating the effect of conformation and intermolecular interactions on NMR chemical shifts. Such calculations are not always difficult, but can be very helpful in interpreting experimental results.

In this short review, we demonstrate how the simplest methods of one-dimensional solid-state NMR can be applied to a variety of solid and heterogeneous samples in order to expand the possibilities of their research. These experiments do not require any special hardware or software or much experience in solid state NMR. Only examples nuclei with a spin quantum number of $\frac{1}{2}$ are considered. Neither the general theory of solid-state NMR nor the physical background of these experiments or quadrupolar nuclei specialized NMR experiments are discussed here. A number of books [6-8] and reviews are devoted to these 
topics [9-18]. Only the basics that are necessary to understand the methods in question are presented. This review includes only a very limited number of examples of simple static calculations of NMR parameters using the density functional theory (DFT). More detailed descriptions of these and advanced methods can be found elsewhere [19-23].

\section{Chemical Shift Anisotropy}

One of the main and easiest to measure spectral characteristics of NMR is a chemical shift. Chemical shift is a tensor quantity, the principal components of which are $\delta_{11} \geq \delta_{22} \geq \delta_{33}$. In a powdery sample, the chemical shift of a given molecule depends on its orientation relative to the direction of the applied magnetic field and is $\leq \delta_{11}$ and $\geq \delta_{33}$. For some molecules, these components can be easily represented in the molecular coordinate system. Let us consider ${ }^{15} \mathrm{~N}$ chemical shift of pyridine. When the molecular $\mathrm{C}_{2}$ symmetry axis is along the direction of the applied magnetic field, the rotation of the molecule around this axis does not change the shielding of the ${ }^{15} \mathrm{~N}$ nucleus. This component of the tensor will be labeled as $\delta_{\mathrm{r}}$, Figure 1 top left. The same is true when the direction of the applied magnetic field is normal to the molecular plane and the molecule rotates around this axis. This component will be labeled as $\delta_{\perp}$. The third axis, $\delta_{t}$, lies in the molecular plane and is orthogonal to $\delta_{\mathrm{r}}$ and $\delta_{\perp}$. For pyridine, $\delta_{11}=\delta_{\mathrm{t}}, \delta_{22}=\delta_{\mathrm{r}}$, and $\delta_{33}=\delta_{\perp}$, Figure 1a [24].
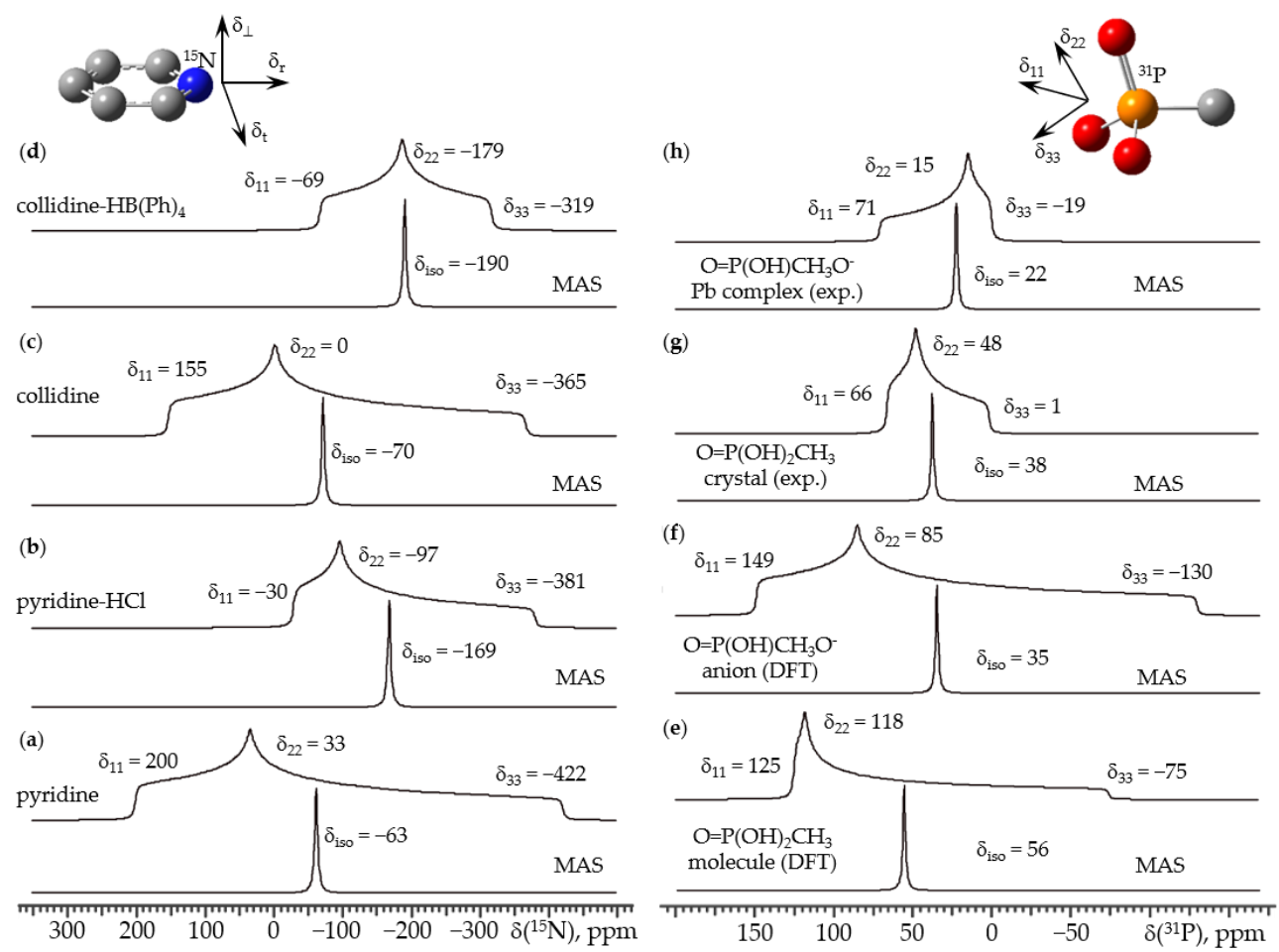

Figure 1. Static and magic-angle spinning (MAS) ${ }^{15} \mathrm{~N}$ and ${ }^{31} \mathrm{P}$ NMR spectra of nitrogen heterocycles (a-d) and methylphosphonic acid (e-h): (a) pyridine, (b) pyridinium chloride, (c) collidine, (d) collidinium tetraphenylborate, (e) methylphosphonic acid, this structure is optimized using DFT, (f) methylphosphonate, DFT optimized, (g) polycrystalline methylphosphonic acid, (h) polycrystalline lead(II) methylphosphonate. ${ }^{15} \mathrm{~N}$ NMR chemical shifts are referenced to liquid nitromethane [24,25]. ${ }^{31} \mathrm{P}$ NMR chemical shifts are referenced to $\mathrm{H}_{3} \mathrm{PO}_{4}\left(85 \%\right.$ in $\left.\mathrm{H}_{2} \mathrm{O}\right)$ [26].

Hydrogen bonding causes significant change in $\delta_{\mathrm{t}}$, but only slightly affects $\delta_{\mathrm{r}}$ and $\delta_{\perp}$ [24]. In the pyridinium cation $\delta_{11}=\delta_{\mathrm{r}}, \delta_{22}=\delta_{\mathrm{t}}$, and $\delta_{33}=\delta_{\perp}$, Figure 1b. Very similar values and changes were observed for 2,4,6-trimethylpyridine (collidine), Figure 1c,d [25]. The fact that the effect of noncovalent interactions on the ${ }^{15} \mathrm{~N}$ NMR chemical shift tensor of pyridines is caused by a significant change of the value of only one of its principle components, $\delta_{t}$, leads to monotonic and characteristic changes in $\delta_{\text {iso }}=\left(\delta_{11}+\delta_{22}+\delta_{33}\right) / 3$. 
For example, for all studied symmetrically substituted pyridines the difference in $\delta_{\text {iso }}\left({ }^{15} \mathrm{~N}\right)$ of the base and its conjugate acid is about $125 \mathrm{ppm}$ [27].

In solution NMR, the anisotropy of chemical shift tensors is averaged out by fast molecular tumbling and only single isotropic chemical shift values are observed, $\delta_{\text {iso }}$. For powdered samples, this anisotropy can be averaged out by magic-angle spinning (MAS) $[6,15,28]$. The signals in MAS spectra become narrow and Gaussian/Lorentzian shaped, Figure 1 bottom spectra. When multiple signals are present in the spectrum, they are either resolved or can be obtained by deconvolution. The signal-to-noise ratio increases significantly since the given integral intensity is distributed in these MAS spectra over a much narrower spectral range.

The direction of the principal components of the chemical shift tensor in the molecular coordinate system is not always user friendly. In the ${ }^{31} \mathrm{P}$ NMR chemical shift tensor of an isolated molecule of methylphosphonic acid, $\delta_{22}$ is directed approximately along the $\mathrm{P}=\mathrm{O}$ bond while $\delta_{33}$ is in the plane between the hydroxyl groups, Figure 1 top right [26]. Deprotonation or noncovalent interactions change these directions. As a result, the observed changes in the ${ }^{31} \mathrm{P}$ NMR chemical shift tensor are difficult to discuss in the molecular coordinate system. The effect of noncovalent interactions on the ${ }^{31} \mathrm{P}$ NMR chemical shift tensor of this molecule is very large. Compare, for example, the tensors of the isolated, noninteracting molecule and of a molecule in the crystal phase, Figure 1e,g, or the tensors of an isolated molecule of methylphosphonate and of the same molecule in a polycrystalline sample of this anion in the complex with Pt, Figure 1f,h. In contrast, changes in the corresponding $\delta_{\text {iso }}$ are quite moderate. In this case, it is no longer obvious whether the significant loss of information about the system is compensated for by a significant increase in the signal-to-noise ratio.

\section{Cross-Polarization}

When the nuclei under study are nuclei other than ${ }^{1} \mathrm{H},{ }^{19} \mathrm{~F}$, and ${ }^{31} \mathrm{P}$, the sensitivity of the method becomes a bottleneck. In particular, for ${ }^{13} \mathrm{C}$ and ${ }^{29} \mathrm{Si} \mathrm{NMR}$, whose natural abundances are $1 \%$ and $5 \%$, one would prefer to use the original samples without laborious isotope enrichment. These dilute spins can borrow magnetization from protons that results in a signal enhancement up to a factor of $4\left({ }^{13} \mathrm{C}\right)$ and $5\left({ }^{29} \mathrm{Si}\right)$. This technique is called cross-polarization (CP). Another advantage of this technique that the recycle delay required to avoid signal saturation is controlled by the $T_{1}$ relaxation time of the ${ }^{1} \mathrm{H}$ nuclei, not that of the dilute spins. The former in most cases is several times shorter than the latter. Note that $\mathrm{CP}$ can be combined with other methods that enhance relaxation. Figure 2a,b shows ${ }^{13} \mathrm{C}\left\{{ }^{1} \mathrm{H}\right\}$ CPMAS NMR spectra of two filter paper (100\% cellulose) samples. The best recycle delays for a dry paper sample and the same paper moistened with an aqueous solution of the 2,2,6,6-tetramethylpiperidinyloxyl radical (TEMPO) were 5.0 and $0.5 \mathrm{~s}$, respectively. In the latter sample, fluctuating local magnetic fields induced by unpaired electron spins return excess of nuclear spin energy in the form of heat to the surroundings. However, everything has a price. First, the presence of the magnetic dipoledipole interaction between the proton spins and the spins under observation requires the use of a high-power heteronuclear decoupling, which is designated here as $\left\{{ }^{1} \mathrm{H}\right\}$. In many cases, higher decoupling strengths provide better signal-to-noise ratios. However, it is dangerous to use a high-power decoupling for more than a few tens of milliseconds. The rf-coil can be damaged. If you are not sure about the correctness of the parameters, contact a specialist. Second, the gain obtained by $\mathrm{CP}$ depends on the magnetic dipole-dipole interaction between the dilute spins and neighboring protons. Therefore, the observed gain is nonuniform for heterogeneous samples. Figure $2 \mathrm{c}, \mathrm{d}$ shows ${ }^{29} \mathrm{Si}\left\{{ }^{1} \mathrm{H}\right\}$ MAS NMR spectra of an MCM-41 mesoporous silica sample collected without and with CP. The relative intensities corresponding to chemically different silicon atoms differ significantly, because $\mathrm{CP}$ specifically enhances the magnetization of surface siloxane groups [29]. Be critical when evaluating sample composition using CP NMR spectra. 


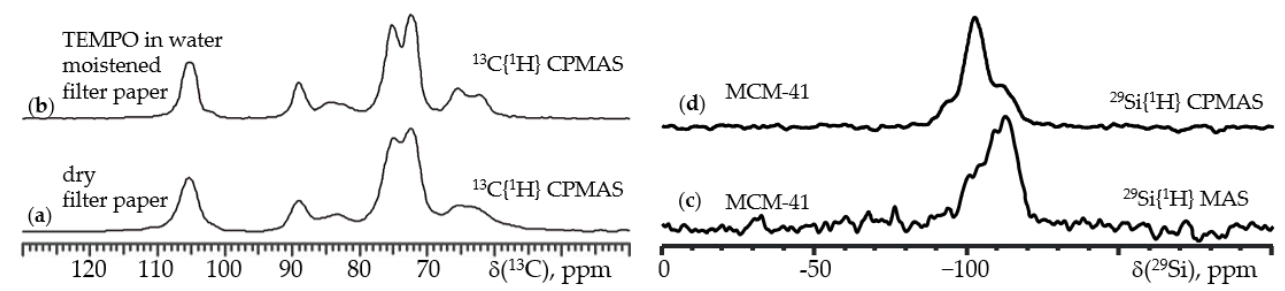

Figure 2. ${ }^{13} \mathrm{C}\left\{{ }^{1} \mathrm{H}\right\}$ CPMAS NMR spectra of (a) dry filter paper $(\mathbf{b})$ the same paper moistened with an aqueous solution of 2,2,6,6-tetramethylpiperidinyloxyl radical (TEMPO). ${ }^{29} \mathrm{Si}\left\{{ }^{1} \mathrm{H}\right\}$ MAS NMR of an MCM-41 mesoporous silica sample (c) without and (d) with cross-polarization (CP). The ${ }^{29}$ Si spectra are adapted from [29].

This problem is not specific to ${ }^{29} \mathrm{Si}$ NMR. Figure 3 shows the ${ }^{15} \mathrm{~N}\left\{{ }^{1} \mathrm{H}\right\}$ CPMAS NMR spectra of a lyophilized sample of the mutant H64A of human carbonic anhydrase II [30]. The natural abundant ${ }^{15} \mathrm{~N}$ nuclei of the peptide backbone contribute to a peak at around $120 \mathrm{ppm}$. This sample contained doubly ${ }^{15} \mathrm{~N}$ labeled 4-methylimidazole. These nitrogen nuclei resonate at 253 and $173 \mathrm{ppm},=\mathrm{N}$ - and $>\mathrm{NH}$, respectively. However, only the latter is observed when using the standard $\mathrm{CP}$ pulse sequence, Figure 3a. The magnetization transfer to $=\mathrm{N}$ - could probably be improved by using a longer cross-polarization contact time. However, this approach has a number of associated problems. Instead, before the FID was acquired, the ${ }^{15} \mathrm{~N}$ magnetization was directed for $1 \mathrm{~s}$ along the direction of the applied magnetic field (Z-filter sequence). Under these conditions, the magnetization of the $>\mathrm{NH}$ nitrogen atoms can be transferred to the $=\mathrm{N}$ - nitrogen atoms (spin diffusion). This equilibration process was successful but not complete, and an intensity difference remained, Figure $3 \mathrm{~b}$.

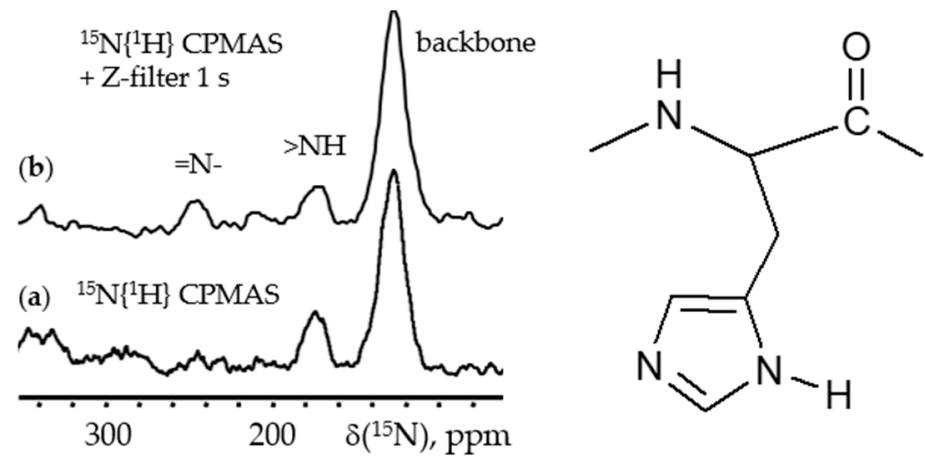

Figure 3. ${ }^{15} \mathrm{~N}\left\{{ }^{1} \mathrm{H}\right\}$ CPMAS NMR spectra of a lyophilized sample of the mutant H64A of human carbonic anhydrase II [30]. (a) CP pulse sequence with a cross-polarization contact time of $3 \mathrm{~ms}$. (b) The ${ }^{15} \mathrm{~N}$ magnetizations is equilibrated for $1 \mathrm{~s}$ using a Z-filter sequence.

\section{Calculation of NMR Chemical Shifts}

Theoretical calculations provide the absolute chemical shielding tensor, $\sigma$, the components of which are $\sigma_{11} \leq \sigma_{22} \leq \sigma_{33} . \sigma_{\text {iso }}=\left(\sigma_{11}+\sigma_{22}+\sigma_{33}\right) / 3$. The experimentally reported chemical shift, $\delta$, is measured relative to the absolute chemical shielding of a reference, $\delta=\left(\sigma^{\text {ref }}-\sigma\right) /\left(1-\sigma^{\text {ref }}\right) . \sigma^{\text {ref }}$ is of the order of $10^{-4}$ that is $\delta \approx\left(\sigma^{\text {ref }}-\sigma\right)$. Therefore, in order to compare the values of the experimentally observed $\delta$ and calculated $\sigma$, a $\sigma^{\text {ref }}$ value is needed. For example, $\delta\left({ }^{31} \mathrm{P}\right) \equiv 0 \mathrm{ppm}$ for $85 \% \mathrm{H}_{3} \mathrm{PO}_{4}$ in $\mathrm{H}_{2} \mathrm{O}$. This value is easy to measure but not to calculate. Neither the polarizable continuum model (PCM) nor solvation model based on density (SMD) approaches [31-33] can satisfactorily simulate the effect of solvation on the chemical shielding of $\mathrm{H}_{3} \mathrm{PO}_{4}$. Therefore, $\delta\left({ }^{31} \mathrm{P}\right)$ is known, but the corresponding $\sigma\left({ }^{31} \mathrm{P}\right)$ cannot be calculated, so $\sigma^{\text {ref }}\left({ }^{31} \mathrm{P}\right)$ remains unknown. For ${ }^{31} \mathrm{P}$ this problem has been solved recently [34]. The values of $\delta\left({ }^{31} \mathrm{P}\right)$ were measured for a number of solids in which $\delta\left({ }^{31} \mathrm{P}\right)$ was not influenced by noncovalent interactions, Figure 4 . The conformation of the molecules was taken from X-ray diffraction (XRD) data. For these conformations were calculated the values of $\sigma\left({ }^{31} \mathrm{P}\right)$, from which the mean value, $\sigma^{\text {ref }}\left({ }^{31} \mathrm{P}\right)$, 
was evaluated. The margin of error of $\sigma^{\text {ref }}\left({ }^{31} \mathrm{P}\right)$ ranged from \pm 9 to $\pm 4 \mathrm{ppm}$, depending on the level of approximation. The best results were obtained for the specialized pcSseg-3 basis set [35] and the $\omega$ B97XD DFT functional [36]. However, smaller basis sets and simpler DFT functionals also provide satisfactory accuracy. The reported molecular structures can be used to determine $\sigma^{\text {ref }}\left({ }^{31} \mathrm{P}\right)$ for any approximation of interest [34].

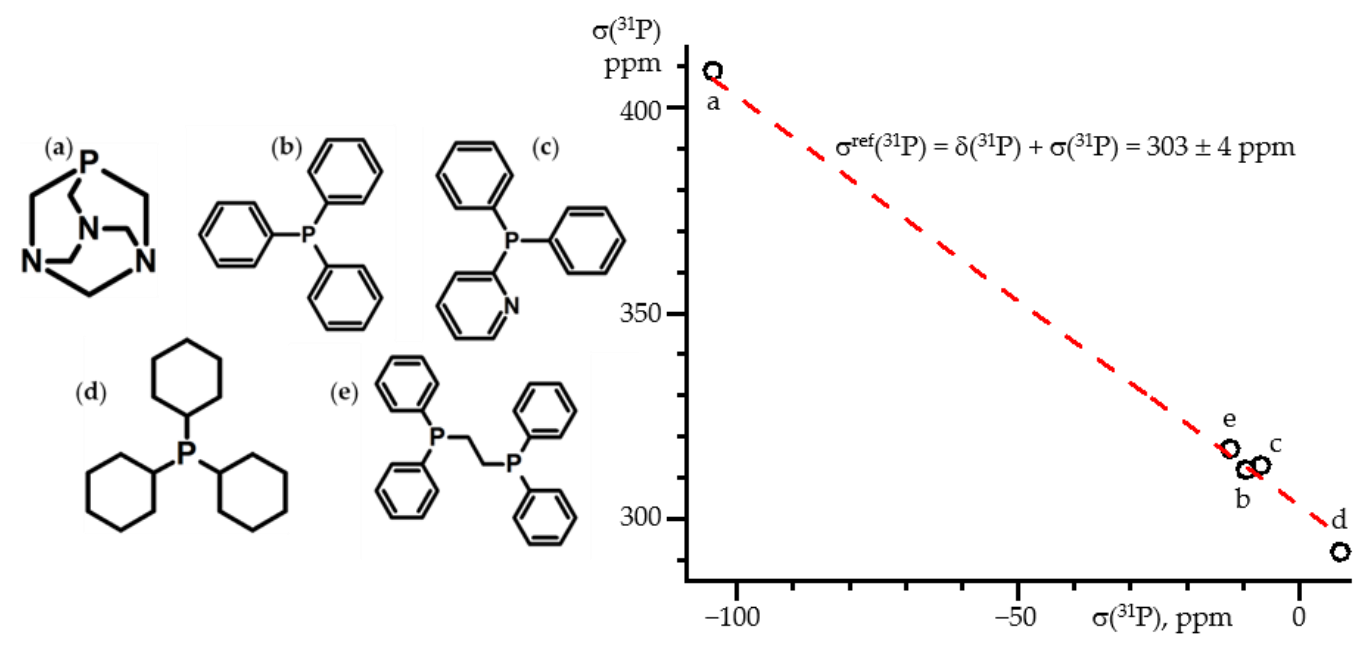

Figure 4. $\sigma\left({ }^{31} \mathrm{P}\right)$ calculated under the pcSseg-3/ $\omega$ B97XD approximation as a function of the experimental $\delta\left({ }^{31} \mathrm{P}\right)$ of polycrystalline 1,3,5-triaza-7-phosphaadamantane (a), triphenylphosphine (b), diphenyl-2-pyridylphosphine (c), tricyclohexylphosphane (d), and 1,2-bis(diphenylphosphino) ethane (e) [34].

Note that for molecules with large dipole moments, the measured magnetic shielding of ${ }^{31} \mathrm{P}$ depends on the electric field generated by surrounding molecules [37]. As a result, there is a large deviation between the observed and predicted $\delta\left({ }^{31} \mathrm{P}\right)$ even if the conformation of the molecules is known and the shielding does not depend on noncovalent intermolecular interactions. The results obtained indicate that the field strength experienced by these molecules in crystals is similar to that in polar solvents. This effect cannot be satisfactorily reproduced within the PCM and SMD approaches. However, it can be successfully accounted for by the adduct under field approach (AuF) [37]. The dependence of the electron density on the applied electric field and the associated changes in chemical and spectral properties were widely studied [38-43]. Within the AuF approach, both the structure and NMR properties were calculated in the presence of an external electric field. This external electric field is a tool to put pressure on the electron density of the molecule under investigation in order to simulate changes caused by the environment. A detailed description of this method can be found elsewhere [44-46].

\section{5. ${ }^{1} \mathrm{H}$ NMR}

In most solids, protons form strongly coupled spin networks. As a result, high resolution ${ }^{1} \mathrm{H}$ NMR in solids requires ultrafast MAS or specific pulse sequences. A detailed description of these methods can be found elsewhere [47-53]. The problem is absent when protons either are diluted or possess high mobility.

Figure 5 shows ${ }^{1} \mathrm{H}$ MAS NMR spectra of polycrystalline samples of pyridinium tetrakis [3,5-bis(trifluoromethyl)-phenyl]-borate and the proton-bound homodimer of pyridine tetrakis [3,5-bis(trifluoromethyl)-phenyl]-borate [54,55]. The chemical shifts of mobile protons at 12.0 and $20.7 \mathrm{ppm}$ are clearly detected at small MAS rates due to the use of pyridine- $d_{5}$, Figure $5 \mathrm{a}$,b. In these samples, protons were diluted spins and proton-proton magnetic dipolar interactions were weak. 


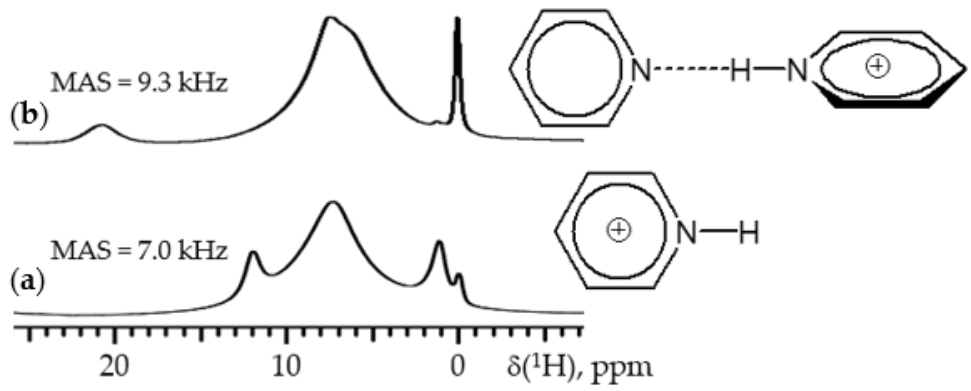

Figure 5. ${ }^{1} \mathrm{H}$ MAS NMR spectra of polycrystalline samples of (a) the conjugate acid and (b) the proton-bound homodimer of pyridine- $d_{5}$ at $300 \mathrm{~K}$ [54].

Figure 6a shows ${ }^{1} \mathrm{H}$ MAS NMR spectra of dry mesoporous silica MCM-41. The distance between the surface silanol groups of MCM-41 is about 3-6 $\AA 29,56]$ while the rotation around the Si-O bond is most likely not hindered. Therefore, the proton-proton magnetic dipolar interactions are weak and a narrow signal belonging to these surface silanol groups is present at $1.8 \mathrm{ppm}$ in different types of porous silica. When this silica is loaded with pyridine, the chemical shift of these groups increases to the limiting value of $9.9 \mathrm{ppm}$, Figure $6 \mathrm{~b}$ [57]. The resonance is broadened because of the hydrogen bonding exchange. The vanishing of the original resonance of the noninteracting silanol groups shows that all these groups are accessible for pyridine. It is not always so. In other samples and for other guests, a gradual redistribution of signal intensity between noninteracting and interacting sites can be observed [58].

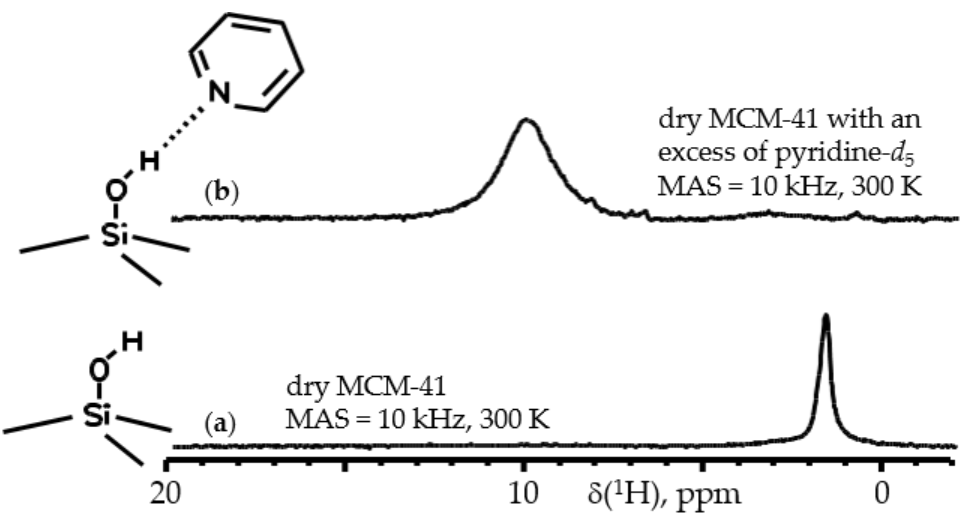

Figure 6. ${ }^{1} \mathrm{H}$ MAS NMR spectra of (a) dry mesoporous silica MCM-41 and (b) the same sample loaded with an excess of pyridine- $d_{5}$ at $300 \mathrm{~K}$. The spectra are adapted from [57].

An NMR study of fluids in confinement is in demand today. The main attention has been focused on water and water-alcohol mixtures [59-65]. Some other substances have been studies as well [66-70]. Interaction with the surface causes a change in the melting/freezing point of the adsorbate [71-75]. When the confinement is not very tight and the surface concentration is below monolayer coverage, the reorientation of adsorbed molecules is fast on a millisecond time scale and their ${ }^{1} \mathrm{H}$ NMR linewidths are small [76]. Specific examples are not considered here in detail because the methods, temperature ranges, filling factors, and other parameters used depend on the host, the guest, and the property in question.

There is a general method for investigating various local spaces of powdery porous solids containing surface $\mathrm{OH}$-groups using ${ }^{1} \mathrm{H}$ NMR [77]. Consider a sample of MCM41 mesoporous silica loaded with 4-methyl-1H-pyrazole (MPz). Pyrazole molecules are distributed over three local spaces. These spaces are shown in Figure 7: (a) internal pores of a given crystallite, (b) an external space between crystallites, and (c) an axial void space at the center of the NMR rotor because the crystallites are compressed toward the NMR 
rotor walls due to a fast MAS rotation. MPz is liquid at room temperature and can be easily loaded onto porous materials where it forms hydrogen bonds with surface OH-groups. At room temperature, the coalesced $\mathrm{NH} / \mathrm{OH}$ signal exhibits some exchange broadening, which disappears at high temperatures. On the other hand, up to at least $400 \mathrm{~K}$, the exchange of MPz molecules between the different local spaces is slow on the NMR time scale. At this temperature, ${ }^{1} \mathrm{H}$ NMR spectra contain three resolved $\mathrm{NH} / \mathrm{OH}$ signals, one for each of the local spaces, Figure $7 \mathrm{~d}$. This is because the $\mathrm{OH} / \mathrm{NH}$ ratios are different in these local spaces. These ratios can be measured from the relative integral intensity of the respective signals. The $\mathrm{OH} / \mathrm{NH}$ ratios depend on the $\mathrm{MPz} /$ host ratio used. Therefore, they provide insight into the pore filling mechanisms, surface/volume, volume/volume, and surface/surface ratios of the different spaces. Note that the volumes of the external void spaces of the MCM-41 and SBA-15 mesoporous silica studied turned out to be larger than those of the internal pores. The surface areas of the external spaces were much smaller than those of the internal pores, although in the case of SBA-15 this difference was not significant [77].
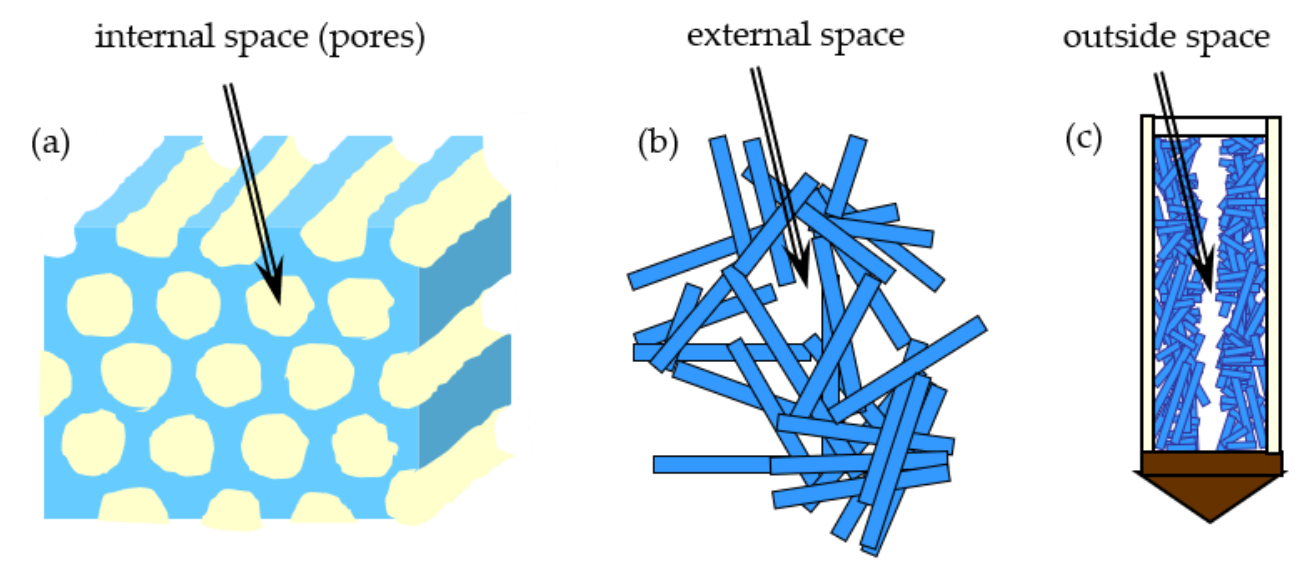

(d)

averaged $\mathrm{NH} / \mathrm{SiOH}$

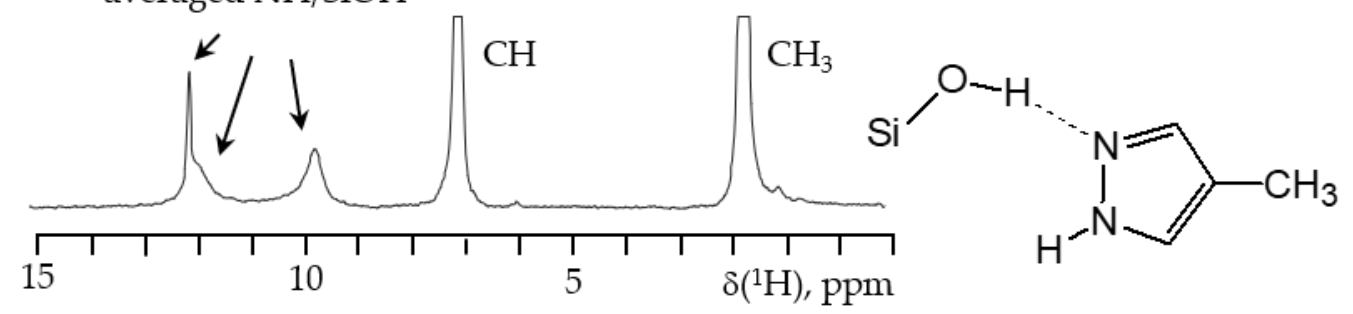

Figure 7. Local spaces in a sample of powdery porous solid [77]. (a) An internal pore of a given crystallite. (b) An external space between crystallites. (c) The packing of the crystallites inside the NMR rotor due to the MAS centrifugal forces. (d) ${ }^{1} \mathrm{H}$ MAS NMR spectrum of 4-methyl-1H-pyrazole embedded MCM-41 mesoporous silica at $398 \mathrm{~K}$.

\section{6. ${ }^{15} \mathrm{~N}$ NMR}

${ }^{15} \mathrm{~N}$ NMR is not among the most popular routine NMR methods. The natural abundance of this isotope is $0.4 \%$, and the strength of its magnetic moment is rather small. However, in some cases, the efforts spent on obtaining isotopically enriched compounds pay off with the results obtained. As explained in Section 2, the isotropic ${ }^{15} \mathrm{~N}$ NMR chemical shift of symmetrically substituted pyridines exhibits significant and characteristic changes upon hydrogen bonding. Figure 8 a shows average $\mathrm{N} \cdots \mathrm{H}$ distances obtained by ${ }^{15} \mathrm{~N}$ NMR of collidine $-{ }^{15} \mathrm{~N}$-acid complexes as a function of $\delta_{\text {iso }}\left({ }^{15} \mathrm{~N}\right)$ [25]. Here $\delta_{\text {iso }}\left({ }^{15} \mathrm{~N}\right) \equiv 0$ ppm for frozen collidine and is about 125 ppm for collidinium [27]. This dependence can be used for any symmetrically substituted pyridine. For a detailed discussion about geometric and NMR parameter correlations, refer to other publications $[78,79]$. The ${ }^{15} \mathrm{~N}$ NMR spectrum 
of an ${ }^{15} \mathrm{~N}$-enriched pyridine derivative can be easily measured in solution [80-82], crystals [55,83], and polymeric materials [84], which provides insight into the hydrogen bond geometry and the protonation state of this base. $\delta_{\text {iso }}\left({ }^{15} \mathrm{~N}\right)$ is sensitive to other noncovalent interactions as well $[85,86]$. It is quite probable that $\delta_{\text {iso }}\left({ }^{15} \mathrm{~N}\right)$ characteristically correlates with some parameters of these interactions. However, no such analysis has been carried out to date.

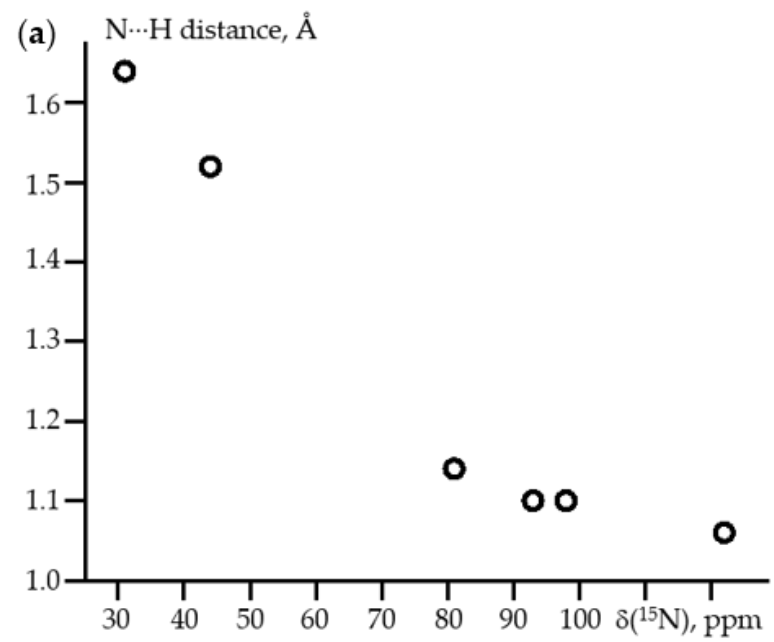

(i)

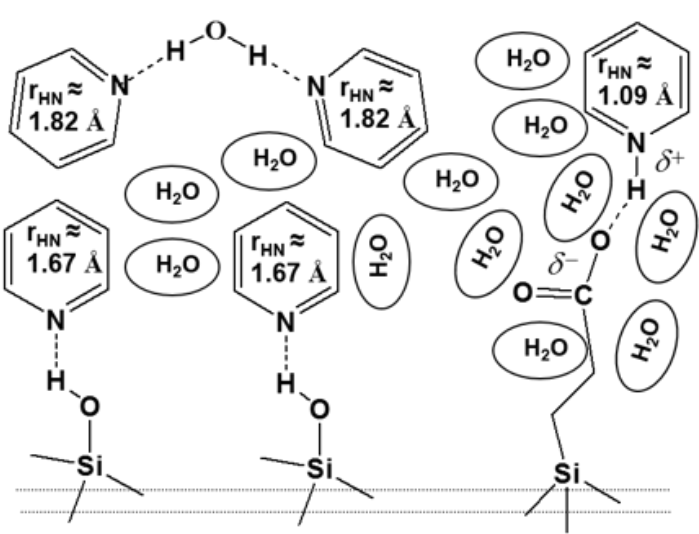

(h)

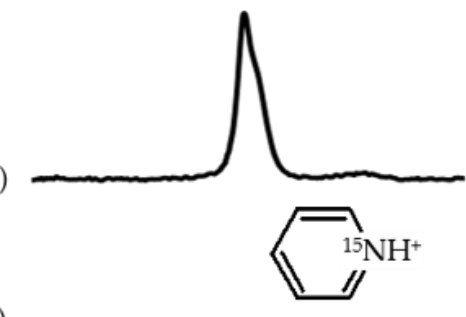

(g)

(f)

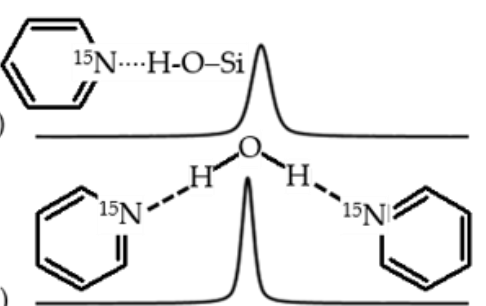

(d)

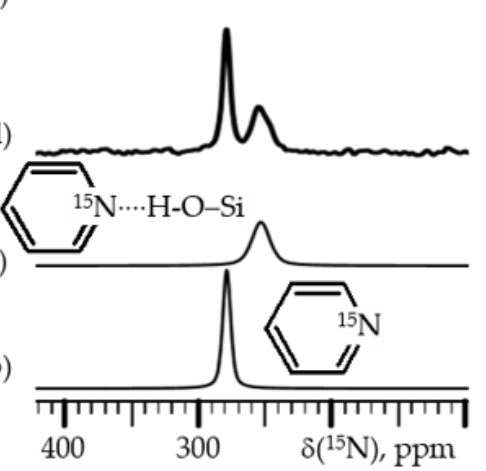

Figure 8. (a) Average $\mathrm{N} \cdots \mathrm{H}$ distances obtained by ${ }^{15} \mathrm{~N}$ NMR of collidine- ${ }^{15} \mathrm{~N}$-acid complexes as a function of $\delta_{\text {iso }}\left({ }^{15} \mathrm{~N}\right)$. Here $\delta_{\text {iso }}\left({ }^{15} \mathrm{~N}\right)$ is $0 \mathrm{ppm}$ for frozen collidine [25]. ${ }^{15} \mathrm{~N}\left\{{ }^{1} \mathrm{H}\right\}$ CPMAS NMR spectra at $130 \mathrm{~K}$ of pyridine- ${ }^{15} \mathrm{~N}$ loaded onto a dry unfunctionalized SBA-15 mesoporous silica sample (d) and a propionic acid functionalized SBA-15 in the presence of water $(\mathbf{h})$. The observed signals were attributed to frozen pyridine $(\mathbf{b})$, pyridine hydrogen bonded to silanol groups $(\mathbf{c}, \mathbf{f})$, pyridinium (g), and pyridine-water-pyridine complex (e). Here $\delta_{\text {iso }}\left({ }^{15} \mathrm{~N}\right)$ is $0 \mathrm{ppm}$ for ${ }^{15} \mathrm{NH}_{4} \mathrm{Cl}$ and $276 \mathrm{ppm}$ for frozen pyridine [87]. (i) Schematic representation of species present in the propionic acid functionalized SBA-15 loaded with pyridine/water [87].

Pyridines $-{ }^{15} \mathrm{~N}$ appears to be the best NMR probes for studying acidic active sites in porous solids. Figure $8 \mathrm{~d}$ shows the ${ }^{15} \mathrm{~N}\left\{{ }^{1} \mathrm{H}\right\}$ CPMAS NMR spectrum of pyridine- ${ }^{15} \mathrm{~N}$ loaded onto a dry unfunctionalized SBA-15 mesoporous silica sample [87]. The spectrum was measured at $130 \mathrm{~K}$ and referenced to ${ }^{15} \mathrm{NH}_{4} \mathrm{Cl}$. In this scale, frozen pyridine resonates at $276 \mathrm{ppm}$. This spectrum contains the signals of frozen pyridine and of pyridine hydrogen bonded to the surface silanol groups, Figure $8 b, c$. The surface density of these groups can be measured from the relative integral intensity of these signals. It is about $2.9 \mathrm{~nm}^{-2}$ for MCM-41 and $3.7 \mathrm{~nm}^{-2}$ for SBA-15 [57]. Figure 8h shows the ${ }^{15} \mathrm{~N}\left\{{ }^{1} \mathrm{H}\right\}$ CPMAS NMR spectrum of pyridine $-{ }^{15} \mathrm{~N}$ loaded onto a propionic acid functionalized SBA-15 sample in the presence of water. This spectrum contains the signals of 2:1 pyridine:water complex [88], of pyridine-HOSi, and of pyridinium, Figure 8e,f,g. The analysis of these spectra explains 
the mechanism of water's effect on the surface acidity. Water does not change the acidity of the surface silanol groups, since it cannot solvate them. When unfunctionalized silica is loaded with a pyridine/water mixture with an excess of pyridine, pyridine molecules are distributed between the pyridine-HOSi and 2:1 pyridine:water phases, Figure 8i. The same phases are present in the case of the propionic acid functionalized SBA-15. In addition, there are pyridine molecules that interact with the carboxyl moieties. These molecules are protonated because these fragments are solvated with water, Figure $8 \mathrm{i}$. Note that in the absence of water, the geometry of hydrogen bonds of the pyridine-HOSi and pyridineHOOC surface complexes is the same [87]. This means that, in the absence of water, the proton-donating ability of silanol groups is equal to that of propionic acid.

The surface silanol groups can only be deprotonated with very strong bases such as 4dimethylaminopyridine and 4-diethyl-2,6-di-tert-butylaminopyridine [56]. The protonated molecules remain immobilized on the surface at room temperature, but can freely rotate around their $\mathrm{C}_{2}$ molecular axis. Their concentration is not affected by water, and water does not participate in or coordinate around the protonated species. The situation is different when the silica surface is functionalized with sulfonic or phosphonic acids. These acidic groups always protonate pyridine because these materials contain about six water molecules per acid moiety even after drying at $420 \mathrm{~K}$ in high vacuum [89]. Each sulfonic acid moiety interacts with one pyridine molecule, while each phosphonic acid moiety can interact simultaneously with two pyridine molecules. In all considered cases, the geometry of hydrogen bonds can be measured from the experimentally observed ${ }^{15} \mathrm{~N}$ NMR chemical shifts.

As has been explained in Chapter 2, chemical shift is a tensor quantity. Therefore, the line shapes of NMR signals depend on the rotational diffusion. This effect can be used to study the surface diffusion of adsorbed molecules. Figure 9 shows the ${ }^{15} \mathrm{~N}\left\{{ }^{1} \mathrm{H}\right\} \mathrm{NMR}$ spectra of pyridine $-{ }^{15} \mathrm{~N}$ loaded onto MCM-41 and SBA-15 mesoporous silica [57]. These spectra were measured at $300 \mathrm{~K}$ and are referenced to ${ }^{15} \mathrm{NH}_{4} \mathrm{Cl}$. Less than a monolayer was occupied in both samples. Under these conditions, pyridine does not leave the surface, and its surface diffusion is fast on the NMR time scale. The acidity of the surface silanol groups does not depend on the type of silica. MAS averages out shielding anisotropy, which is weaker than the spinning frequency. As a result, the ${ }^{15} \mathrm{~N}\left\{{ }^{1} \mathrm{H}\right\}$ MAS NMR spectra are the same for both samples, Figure 9a,c. On the other hand, the static ${ }^{15} \mathrm{~N}\left\{{ }^{1} \mathrm{H}\right\}$ NMR spectrum of the MCM-41 sample demonstrates the residual shielding anisotropy, which is absent in the case of the SBA-15 sample, Figure 9b,d. The presence of this residual shielding anisotropy indicates the very low degree of roughness of the inner surfaces of this MCM-41 sample. Please refer to the original paper for a detailed analysis [57].

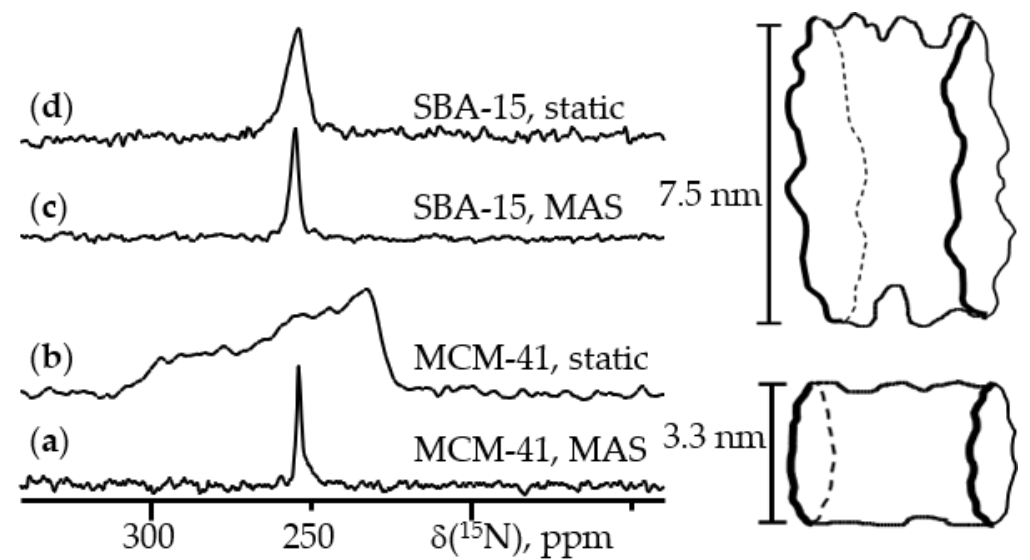

Figure 9. ${ }^{15} \mathrm{~N}\left\{{ }^{1} \mathrm{H}\right\} \mathrm{CP}$ NMR spectra at $300 \mathrm{~K}$ of pyridine- ${ }^{15} \mathrm{~N}$ loaded onto mesoporous silica [57]. (a) MAS spectrum, MCM-41, (b) static spectrum, MCM-41, (c) MAS spectrum, SBA-15, and (d) static spectrum, SBA-15MCM-41. Here $\delta_{\text {iso }}\left({ }^{15} \mathrm{~N}\right)$ is $0 \mathrm{ppm}$ for ${ }^{15} \mathrm{NH}_{4} \mathrm{Cl}$ and $276 \mathrm{ppm}$ for frozen pyridine. 


\section{7. ${ }^{31} \mathrm{P}$ NMR}

The ${ }^{31} \mathrm{P}$ isotope is present in $100 \%$ natural abundance, has a spin quantum number of $1 / 2$ and a chemical shift range of more than $400 \mathrm{ppm} .{ }^{31} \mathrm{P}$ NMR can be routinely used in the evaluation of the structure of organic complexes in solution [90,91] and solids [92-94] including organometallic compounds [26,95-98]. Molecules containing phosphorus are very convenient NMR probes for studying mobility at interfaces [99-101]. For example, ${ }^{31} \mathrm{P}$ NMR has been used to elucidate thermal and hydration effects on the mobility of compact, branched, and bulky pharmaceutical molecules loaded in submonolayer amounts onto mesoporous silica [102]. Great progress has been achieved in our understanding of the effects of noncovalent interactions on the ${ }^{31} \mathrm{P}$ chemical shift of $\mathrm{P}=\mathrm{O}$ groups $[26,103,104]$. However, $\mathrm{P}=\mathrm{O}$ groups can form two noncovalent interactions simultaneously [105-107]. Since the phosphorus atom of the $\mathrm{P}=\mathrm{O}$ group is not directly involved in intermolecular interactions, the changes of its isotropic chemical shift is not strictly specific to a certain interaction, and different structures can result in similar values [108]. In addition, the shielding may depend on the conformation of the molecule [26]. Consequently, variations in $\delta_{\text {iso }}\left({ }^{31} \mathrm{P}\right)$ caused by noncovalent interactions and conformational changes cannot always be interpreted.

On the other hand, there are molecules in which $\delta\left({ }^{31} \mathrm{P}\right)$ depends only on interactions of a certain nature. In such cases, NMR allows very accurate analysis of spectral features [109]. For example, 1,3,5-triaza-7-phosphaadamantane (PTA, Figure 10a) is a rigid and relatively chemically inert molecule. In acidic solution, PTA would be protonated at one of its nitrogen atoms. This protonation results in a $6 \mathrm{ppm}$ change in $\delta_{\text {iso }}\left({ }^{31} \mathrm{P}\right)$ [110]. In contrast, when PTA is coordinated to transition metals, its chemical shift varies in a wide range [111]. Figure 10b shows the proposed structure of $\mathrm{Hal}_{2} \mathrm{Hg}(\mathrm{PTA})$ complexes in crystals $(\mathrm{Hal}=\mathrm{Cl}, \mathrm{Br}$, I). This structure is adapted from [112]. In PTA $\delta_{\text {iso }}\left({ }^{31} \mathrm{P}\right)=-104.3 \mathrm{ppm}$ [34], while changes to $-38.3,-44.1$, and -61.4 in $\mathrm{Cl}_{2} \mathrm{Hg}(\mathrm{PTA}), \mathrm{Br}_{2} \mathrm{Hg}(\mathrm{PTA})$, and $\mathrm{I}_{2} \mathrm{Hg}(\mathrm{PTA})$ [112]. Therefore, ${ }^{31} \mathrm{P}$ NMR of organometallic complexes of PTA can be very informative. The structures of these $\mathrm{Hal}_{2} \mathrm{Hg}(\mathrm{PTA})$ complexes are difficult to adapt for calculations. However, there is another important application of ${ }^{31} \mathrm{P}$ NMR. Consider an organometallic complex in which the metal is coordinated with a phosphorus atom. In many cases, the structure of this complex is determined from XRD, while $\delta_{\text {iso }}\left({ }^{31} \mathrm{P}\right)$ is measured in solution [113-117]. If this value can be reproduced in calculations using the structure of the crystalline phase, then the transition to solution has no significant effect on the structure. If this is not the case, then the experimentally reported $\delta_{\text {iso }}\left({ }^{31} \mathrm{P}\right)$ is either not related to the proposed structure, or the structure is labile. Note that such calculations can be done using moderate basis sets [118].

(a)

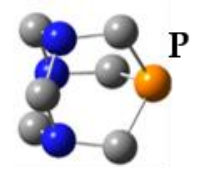

(b)

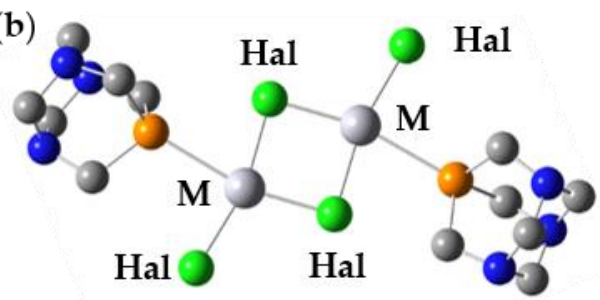

Figure 10. The structure of (a) 1,3,5-triaza-7-phosphaadamantane (PTA) and (b) the proposed structure of $\mathrm{Hal}_{2} \mathrm{Hg}(\mathrm{PTA})$ complexes in crystals $(\mathrm{Hal}=\mathrm{Cl}, \mathrm{Br}$, I) [112].

\section{Conclusions}

Solid-state NMR can do a lot and does not always require excessive efforts. Its advantages are especially noticeable for polycrystalline, amorphous, and heterogeneous samples. It is these systems that are especially difficult to study by other spectral methods. Only a small set of the simplest but broadly applicable methods are discussed here. There are many other powerful and specialized techniques out there today. You can get acquainted with them using the references listed in the Introduction. Two-dimensional solid-state NMR methods are rapidly developing and becoming available for widespread 
use [119-121]. Since 2008, the annual number of publications on "solid-state NMR" has exceeded 2000 [122]. We hope that this review will help some research to include solid-state NMR in the list of spectral methods they actively use.

Author Contributions: Conceptualization, I.G.S. and H.-H.L.; methodology, I.G.S. and H.-H.L.; software, I.G.S. and H.-H.L.; resources, I.G.S.; data curation, I.G.S.; writing-original draft preparation, I.G.S.; writing-review and editing, I.G.S. and H.-H.L.; visualization, I.G.S. and H.-H.L.; funding acquisition, I.G.S. Both authors have read and agreed to the published version of the manuscript.

Funding: This research received no external funding. The APC was funded by MDPI.

Institutional Review Board Statement: Not applicable.

Informed Consent Statement: Not applicable.

Data Availability Statement: Data sharing is not applicable to this article.

Conflicts of Interest: The authors declare no conflict of interest.

\section{References}

1. Porter, A.L.; Rafols, I. Is science becoming more interdisciplinary? Measuring and mapping six research fields over time. Scientometrics 2009, 81, 719-745. [CrossRef]

2. Melnikova, D.L.; Badrieva, Z.F.; Kostin, M.A.; Maller, C.; Stas, M.; Buczek, A.; Broda, M.A.; Kupka, T.; Kelterer, A.-M.; Tolstoy, P.M.; et al. On Complex Formation between 5-Fluorouracil and $\beta$-Cyclodextrin in Solution and in the Solid State: IR Markers and Detection of Short-Lived Complexes by Diffusion NMR. Molecules 2020, 25, 5706. [CrossRef]

3. Antonov, A.S.; Karpov, V.V.; Tupikina, E.Y.; Tolstoy, P.M.; Vovk, M.A. Aggregation Behavior of Lithionaphthalenes in Solution: Experimental and Theoretical Study. Organometallics 2020, 39, 3705-3714. [CrossRef]

4. Jansen, D.; Gramüller, J.; Niemeyer, F.; Schaller, T.; Letzel, M.C.; Grimme, S.; Zhu, H.; Gschwind, R.M.; Niemeyer, J. What is the role of acid-acid interactions in asymmetric phosphoric acid organocatalysis? A detailed mechanistic study using interlocked and non-interlocked catalysts. Chem. Sci. 2020, 11, 4381-4390. [CrossRef]

5. Lokesh, N.; Hioe, J.; Gramüller, J.; Gschwind, R.M. Relaxation Dispersion NMR to Reveal Fast Dynamics in Brønsted Acid Catalysis: Influence of Sterics and H-Bond Strength on Conformations and Substrate Hopping. J. Am. Chem. Soc. 2019, 141, 16398-16407. [CrossRef]

6. Duer, M.J. (Ed.) Solid-State NMR Spectroscopy. Principles and Applications; Blackwell Science Ltd.: Oxford, UK, 2002.

7. Bachmutov, V.I. Solid-State NMR in Materials Science. Principles and Applications; CRC Press: Boca Raton, FL, USA, 2011.

8. Hodgkinson, P. (Ed.) Modern Methods in Solid-State NMR: A Practitioner's Guide; The Royal Society of Chemistry: London, UK, 2018.

9. Buntkowsky, G.; Vogel, M. Small Molecules, Non-Covalent Interactions, and Confinement. Molecules 2020, 25, 3311. [CrossRef]

10. Brunner, E.; Rauche, M. Solid-state NMR spectroscopy: An advancing tool to analyse the structure and properties of metal-organic frameworks. Chem. Sci. 2020, 11, 4297-4304. [CrossRef]

11. Gutmann, T.; Groszewicz, P.B.; Buntkowsky, G. Solid-state NMR of nanocrystals. Annu. Rep. NMR Spectrosc. 2019, 97, 1-82. [CrossRef]

12. Smith, M.E. Recent progress in solid-state nuclear magnetic resonance of half-integer spin low- $\gamma$ quadrupolar nuclei applied to inorganic materials. Magn. Reson. Chem. 2020, 1-44. [CrossRef]

13. Bakhmutov, V.I. Strategies for Solid-State NMR Studies of Materials: From Diamagnetic to Paramagnetic Porous Solids. Chem. Rev. 2011, 111, 530-562. [CrossRef] [PubMed]

14. Hodgkinson, P.; Wimperis, S. Solid-state NMR spectroscopy. Phys. Chem. Chem. Phys. 2009, 11, 6875. [CrossRef] [PubMed]

15. Bryce, D.L.; Bernard, G.M.; Gee, M.; Lumsden, M.D.; Eichele, K.; Wasylishen, R.E. Practical Aspects of Modern Routine Solid-State Multinuclear Magnetic Resonance Spectroscopy: One-Dimensional Experiments. Can. J. Anal. Sci. Spectrosc. 2001, 46, 46-82. [CrossRef]

16. Brown, S.P.; Spiess, W. Advanced Solid-State NMR Methods for the Elucidation of Structure and Dynamics of Molecular, Macromolecular, and Supramolecular Systems. Chem. Rev. 2001, 101, 4125-4156. [CrossRef] [PubMed]

17. Albert, K. NMR investigations of stationary phases. J. Sep. Sci. 2003, 26, 215-224. [CrossRef]

18. Gullion, T. Introduction to rotational-echo, double-resonance NMR. Concepts Magn. Reson. 1998, 10, 277-289. [CrossRef]

19. Kaupp, M.; Bühl, M.; Malkin, V.G. (Eds.) Calculation of NMR and EPR Parameters; Wiley-VCH: Weinheim, Germany, 2004.

20. Pilar, K.; Deng, Z.; Preefer, M.B.; Cooley, J.A.; Clément, R.; Seshadri, R.; Cheetham, A.K. Ab initio computation for solid-state ${ }^{31}$ P NMR of inorganic phosphates: Revisiting X-ray structures. Phys. Chem. Chem. Phys. 2019, 21, 10070-10074. [CrossRef]

21. Grasa, P.; Baker, A.; Combes, C.; Rey, C.; Sarda, S.; Wright, A.J.; Smith, M.E.; Hanna, J.V.; Gervais, C.; Laurencin, D.; et al. From crystalline to amorphous calcium pyrophosphates: A solid state Nuclear Magnetic Resonance perspective. Acta Biomater. 2016, 31, 348-357. [CrossRef] 
22. Medvedev, A.G.; Churakov, A.V.; Prikhodchenko, P.V.; Lev, O.; Vener, M.V. Crystalline Peroxosolvates: Nature of the Coformer, Hydrogen-Bonded Networks and Clusters, Intermolecular Interactions. Molecules 2021, 26, 26. [CrossRef]

23. Charpentier, T. The PAW/GIPAW approach for computing NMR parameters: A new dimension added to NMR study of solids. Solid State Nucl. Magn. Reson. 2011, 40, 1-20. [CrossRef]

24. Solum, M.S.; Altmann, K.L.; Strohmeier, M.; Berges, D.A.; Zhang, Y.; Facelli, J.C.; Pugmire, R.J.; Grant, D.M. ${ }^{15}$ N Chemical Shift Principal Values in Nitrogen Heterocycles. J. Am. Chem. Soc. 1997, 119, 9804-9809. [CrossRef]

25. Lorente, P.; Shenderovich, I.G.; Golubev, N.S.; Denisov, G.S.; Buntkowsky, G.; Limbach, H.-H. ${ }^{1}$ H $/{ }^{15}$ N NMR Chemical Shielding, Dipolar ${ }^{15} \mathrm{~N},{ }^{2} \mathrm{H}$ Coupling and Hydrogen Bond Geometry Correlations in a Novel Serious of Hydrogen-Bonded Acid-Base Complexes of Collidine with Carboxylic Acids. Magn. Reson. Chem. 2001, 39, S18-S29. [CrossRef]

26. Shenderovich, I.G. Effect of Noncovalent Interactions on the ${ }^{31} \mathrm{P}$ Chemical Shift Tensor of Phosphine Oxides, Phosphinic, Phosphonic, and Phosphoric Acids, and Their Complexes with Lead(II). J. Phys. Chem. C 2013, 117, 26689-26702. [CrossRef]

27. Andreeva, D.V.; Ip, B.; Gurinov, A.A.; Tolstoy, P.M.; Denisov, G.S.; Shenderovich, I.G.; Limbach, H.-H. Geometrical Features of Hydrogen Bonded Complexes Involving Sterically Hindered Pyridines. J. Phys. Chem. A 2006, 110, 10872-10879. [CrossRef] [PubMed]

28. Lowe, I.J. Free Induction Decays of Rotating Solids. Phys. Rev. Lett. 1959, 2, 285-287. [CrossRef]

29. Shenderovich, I.G.; Mauder, D.; Akcakayiran, D.; Buntkowsky, G.; Limbach, H.-H.; Findenegg, G.H. NMR Provides Checklist of Generic Properties for Atomic-Scale Models of Periodic Mesoporous Silicas. J. Phys. Chem. B 2007, 111, 12088-12096. [CrossRef] [PubMed]

30. Shenderovich, I.G.; Lesnichin, S.B.; Tu, C.; Silverman, D.N.; Tolstoy, P.M.; Denisov, G.S.; Limbach, H.-H. NMR Studies of Active-Site Properties of Human Carbonic Anhydrase II by using ${ }^{15} \mathrm{~N}$-Labeled 4-Methylimidazole as a Local Probe and Histidine Hydrogen-Bond Correlations. Chem. Eur. J. 2015, 21, 2915-2929. [CrossRef]

31. Cossi, M.; Barone, V.; Cammi, R.; Tomasi, J. Ab initio study of solvated molecules: A new implementation of the polarizable continuum model. Chem. Phys. Lett. 1996, 255, 327-335. [CrossRef]

32. Tomasi, J.; Mennucci, B.; Cammi, R. Quantum mechanical continuum solvation models. Chem. Rev. 2005, 105, $2999-3093$. [CrossRef]

33. Marenich, A.V.; Cramer, C.J.; Truhlar, D.G. Universal solvation model based on solute electron density and on a continuum model of the solvent defined by the bulk dielectric constant and atomic surface tensions. J. Phys. Chem. B 2009, 113, 6378-6396. [CrossRef]

34. Shenderovich, I.G. Experimentally Established Benchmark Calculations of ${ }^{31} \mathrm{P}$ NMR Quantities. Chemistry-Methods 2021, 1, 61-70. [CrossRef]

35. Jensen, F. Segmented Contracted Basis Sets Optimized for Nuclear Magnetic Shielding. J. Chem. Theory Comput. 2015, 11, 132-138. [CrossRef] [PubMed]

36. Chai, J.-D.; Head-Gordon, M. Long-range corrected hybrid density functionals with damped atom-atom dispersion corrections. Phys. Chem. Chem. Phys. 2008, 10, 6615-6620. [CrossRef] [PubMed]

37. Shenderovich, I.G. Electric field effect on ${ }^{31}$ P NMR magnetic shielding. J. Chem. Phys. 2020, 153, 184501. [CrossRef] [PubMed]

38. Nardo, V.M.; Cassone, G.; Ponterio, R.C.; Saija, F.; Sponer, J.; Tommasini, M.; Trusso, S. Electric-Field-Induced Effects on the Dipole Moment and Vibrational Modes of the Centrosymmetric Indigo Molecule. J. Phys. Chem. A 2020, 124, 10856-10869. [CrossRef] [PubMed]

39. Cassone, G.; Sponer, J.; Trusso, S.; Saija, F. Ab initio spectroscopy of water under electric fields. Phys. Chem. Chem. Phys. 2019, 21, 21205-21212. [CrossRef]

40. Dominikowska, J.; Palusiak, M. Tuning Aromaticity of para-Substituted Benzene Derivatives with an External Electric Field. ChemPhysChem 2018, 19, 590-595. [CrossRef]

41. Alkorta, I.; Elguero, J.; Provasi, P.F.; Pagola, G.I.; Ferraro, M.B. Electric field effects on nuclear magnetic shielding of the 1:1 and 2:1 (homo and heterochiral) complexes of $\mathrm{XOOX}^{\prime}\left(\mathrm{X}, \mathrm{X}^{\prime}=\mathrm{H}, \mathrm{CH}_{3}\right)$ with lithium cation and their chiral dis-crimination. J. Chem. Phys. 2011, 135, 104116. [CrossRef]

42. Del Bene, J.E.; Jordan, M.J.T. To What Extent Do External Fields and Vibrational and Isotopic Effects Influence NMR Coupling Constants Across Hydrogen Bonds? Two-Bond Cl-N Spin-Spin Coupling Constants $\left({ }^{2 \mathrm{~h}} \mathrm{JCl}-\mathrm{N}\right)$ in Model ClH: $\mathrm{NH}_{3} \mathrm{Complexes}_{\text {. J. }}$ Phys. Chem. A 2002, 106, 5385-5392. [CrossRef]

43. Ramos, M.; Alkorta, I.; Elguero, J.; Golubev, N.S.; Denisov, G.S.; Benedict, H.; Limbach, H.-H. Theoretical Study of the Influence of Electric Fields on Hydrogen-Bonded Acid-Base Complexes. J. Phys. Chem. A 1997, 101, 9791-9800. [CrossRef]

44. Shenderovich, I.G.; Denisov, G.S. Adduct under Field-A Qualitative Approach to Account for Solvent Effect on Hydrogen Bonding. Molecules 2020, 25, 436. [CrossRef]

45. Shenderovich, I.G.; Denisov, G.S. Modeling of Solute-Solvent Interactions Using an External Electric Field—From Tautomeric Equilibrium in Nonpolar Solvents to the Dissociation of Alkali Metal Halides. Molecules 2021, 26, 1283. [CrossRef]

46. Shenderovich, I.G.; Denisov, G.S. Solvent effects on acid-base complexes. What is more important: A macroscopic reaction field or solute-solvent interactions? J. Chem. Phys. 2019, 150, 204505. [CrossRef] [PubMed]

47. Struppe, J.; Quinn, C.M.; Sarkar, S.; Gronenborn, A.M.; Polenova, T. Ultrafast ${ }^{1}$ H MAS NMR Crystallography for Natural Abundance Pharmaceutical Compounds. Mol. Pharm. 2020, 17, 674-682. [CrossRef] [PubMed]

48. Brown, S.P. Applications of high-resolution ${ }^{1} \mathrm{H}$ solid-state NMR. Solid State Nucl. Magn. Reson. 2012, 41, 1-27. [CrossRef] 
49. Paruzzo, F.M.; Emsley, L. High-resolution ${ }^{1} \mathrm{H}$ NMR of powdered solids by homonuclear dipolar decoupling. J. Magn. Reson. 2019, 309, 106598. [CrossRef]

50. Dudek, M.K.; Kazmierski, S.; Kostrzewa, M.; Potrzebowski, M.J. Solid-State NMR Studies of Molecular Crystals. Annu. Rep. NMR Spectrosc. 2018, 95, 1-81. [CrossRef]

51. Mote, K.R.; Agarwal, V.; Madhu, P.K. Five decades of homonuclear dipolar decoupling in solid-state NMR: Status and outlook. Prog. Nucl. Magn. Reson. Spectrosc. 2016, 97, 1-39. [CrossRef]

52. Vinogradov, E.; Madhu, P.K.; Vega, S. Strategies for high-resolution proton spectroscopy in solid-state NMR. Top. Curr. Chem. 2004, 246, 33-90. [CrossRef]

53. Schnell, I.; Spiess, H.W. High-Resolution ${ }^{1} \mathrm{H}$ NMR Spectroscopy in the Solid State: Very Fast Sample Rotation and MultipleQuantum Coherences. J. Magn. Reson. 2001, 151, 153-227. [CrossRef]

54. Gurinov, A.A.; Lesnichin, S.B.; Limbach, H.-H.; Shenderovich, I.G. How Short is the Strongest Hydrogen Bond in the ProtonBound Homodimers of Pyridine Derivatives? J. Phys. Chem. A 2014, 118, 10804-10812. [CrossRef]

55. Kong, S.; Borissova, A.O.; Lesnichin, S.B.; Hartl, M.; Daemen, L.L.; Eckert, J.; Antipin, M.Y.; Shenderovich, I.G. Geometry and Spectral Properties of the Protonated Homodimer of Pyridine in the Liquid and Solid States. A Combined NMR, X-ray Diffraction and Inelastic Neutron Scattering Study. J. Phys. Chem. A 2011, 115, 8041-8048. [CrossRef]

56. Ip, B.C.K.; Andreeva, D.V.; Buntkowsky, G.; Akcakayiran, D.; Findenegg, G.H.; Shenderovich, I.G. NMR Study of Proton Transfer to Strong Bases on Inner Surfaces of MCM-41. Micropor. Mesopor. Mater. 2010, 134, 22-28. [CrossRef]

57. Shenderovich, I.G.; Buntkowsky, G.; Schreiber, A.; Gedat, E.; Sharif, S.; Albrecht, J.; Golubev, N.S.; Findenegg, G.H.; Limbach, H.-H. Pyridine- ${ }^{15} \mathrm{~N}$ A Mobile NMR Sensor for Surface Acidity and Surface Defects of Mesoporous Silica. J. Phys. Chem. B 2003, 107, 11924-11939. [CrossRef]

58. Grünberg, B.; Emmler, T.; Gedat, E.; Shenderovich, I.; Findenegg, G.H.; Limbach, H.-H.; Buntkowsky, G. Hydrogen Bonding of Water Confined in Mesoporous Silica MCM-41 and SBA-15 Studied by ${ }^{1}$ H Solid-State NMR. Chem. Eur. J. 2004, 10, 5689-5696. [CrossRef]

59. Li, Z.; Rieg, C.; Beurer, A.-K.; Benz, M.; Bender, J.; Schneck, C.; Traa, Y.; Dyballa, M.; Hunger, M. Effect of aluminum and sodium on the sorption of water and methanol in microporous MFI-type zeolites and mesoporous SBA-15 materials. Adsorption 2021, 27, 49-68. [CrossRef]

60. Breynaert, E.; Houlleberghs, M.; Radhakrishnan, S.; Grübel, G.; Taulelle, F.; Martens, J.A. Water as a tuneable solvent: A perspective. Chem. Soc. Rev. 2020, 49, 2557-2569. [CrossRef]

61. Ok, S.; Hwang, B.; Liu, T.; Welch, S.; Sheets, J.M.; Cole, D.R.; Liu, K.-H.; Mou, C.-Y. Fluid Behavior in Nanoporous Silica. Front. Chem. 2020, 8, 734. [CrossRef] [PubMed]

62. Veena, V.S.; Illath, K.; Lazar, A.; Vinod, C.P.; Ajithkumar, T.G.; Jayanthi, S. Distribution of water in the pores of periodic mesoporous organosilicates-A proton solid state MAS NMR study. Phys. Chem. Chem. Phys. 2018, 20, 29351. [CrossRef] [PubMed]

63. Kumari, B.; Brodrecht, M.; Breitzke, H.; Werner, M.; Grünberg, B.; Limbach, H.-H.; Forg, S.; Sanjon, E.P.; Drossel, B.; Gutmann, T.; et al. Mixtures of Alcohols and Water confined in Mesoporous Silica: A Combined Solid-State NMR and Molecular Dynamics Simulation Study. J. Phys. Chem. C 2018, 122, 19540-19550. [CrossRef]

64. Sebastiani, D. Ab-Initio Molecular Dynamics Simulations and Calculations of Spectroscopic Parameters in Hydrogen-Bonding Liquids in Confinement. Z. Phys. Chem. 2018, 232, 973-987. [CrossRef]

65. Kristinaityte, K.; Dagys, L.; Kausteklis, J.; Klimavicius, V.; Doroshenko, I.; Pogorelov, V.; Valevičienė, N.R.; Balevicius, V. NMR and FTIR studies of clustering of water molecules: From low-temperature matrices to nano-structured materials used in innovative medicine. J. Mol. Liq. 2017, 235, 1-6. [CrossRef]

66. Shelyapina, M.G.; Silyukov, O.I.; Lushpinskaya, I.P.; Kurnosenko, S.A.; Mazur, A.S.; Shenderovich, I.G.; Zvereva, I.A. NMR Study of Intercalates and Grafted Organic Derivatives of $\mathrm{H}_{2} \mathrm{La}_{2} \mathrm{Ti}_{3} \mathrm{O}_{10}$. Molecules 2020, 25, 5229. [CrossRef]

67. Klimavicius, V.; Dagys, L.; Chizhik, V.; Balevicius, V. CP MAS Kinetics Study of Ionic Liquids Confined in Mesoporous Silica: Convergence of Non-Classical and Classical Spin Coupling Models. Appl. Magn. Reson. 2017, 48, 673-685. [CrossRef]

68. Buntkowsky, G.; Breitzke, H.; Adamczyk, A.; Roelofs, F.; Emmler, T.; Gedat, E.; Grünberg, B.; Xu, Y.; Limbach, H.-H.; Shenderovich, I.; et al. Structural and Dynamical Properties of Guest Molecules Confined in Mesoporous Silica Materials Revealed by NMR. Phys. Chem. Chem. Phys. 2007, 9, 4843-4853. [CrossRef]

69. Vyalikh, A.; Emmler, T.; Gedat, E.; Shenderovich, I.; Findenegg, G.H.; Limbach, H.-H.; Buntkowsky, G. Evidence of Microphase Separation in Controlled Pore Glasses. Solid State Nucl. Magn. Reson. 2005, 28, 117-124. [CrossRef]

70. Gedat, E.; Schreiber, A.; Findenegg, G.H.; Shenderovich, I.; Limbach, H.-H.; Buntkowsky, G. Stray field gradient NMR reveals effects of hydrogen bonding on diffusion coefficients of pyridine in mesoporous silica. Magn. Reson. Chem. 2001, 39, S149-S157. [CrossRef]

71. Neffati, R.; Judeinstein, P.; Rault, J. Freezing, melting and dynamics of supercooled water confined in porous glass. J. Phys. Condens. Matter 2020, 32, 465101. [CrossRef]

72. Enninful, H.R.N.B.; Schneider, D.; Kohns, R.; Enke, D.; Valiullin, R. A novel approach for advanced thermoporometry characterization of mesoporous solids: Transition kernels and the serially connected pore model. Micropor. Mesopor. Mat. 2020, 309 , 110534. [CrossRef] 
73. Werner, M.; Rothermel, N.; Breitzke, H.; Gutmann, T.; Buntkowsky, G. Recent Advances in Solid State NMR of Small Molecules in Confinement. Isr. J. Chem. 2014, 54, 60-73. [CrossRef]

74. Sattig, M.; Reutter, S.; Fujara, F.; Werner, M.; Buntkowsky, G.; Vogel, M. NMR studies on the temperature-dependent dynamics of confined water. Phys. Chem. Chem. Phys. 2014, 16, 19229-19240. [CrossRef]

75. Grünberg, B.; Grünberg, A.; Limbach, H.-H.; Buntkowsky, G. Melting of Naphthalene Confined in Mesoporous Silica MCM-41. Appl. Marn. Reson. 2013, 44, 189-201. [CrossRef]

76. Szalontai, G. ${ }^{1} \mathrm{H}$ NMR linewidths of small organic guest molecules physisorbed on different mesoporous silicas. J. Mol. Struct. 2020, 1205, 127646. [CrossRef]

77. Torres Barthelemy, V.; Pérez-Hernández, N.; Shenderovich, I.G.; Tolstoy, P.M.; Denisov, G.S.; Limbach, H.-H. NMR-Detected Host-Guest Proton Exchange as a Tool to Explore Surface/Volume Ratios and Fluid Filling of Internal and External Spaces of Porous Solids containing Surface-OH-Groups. J. Phys. Chem. C 2020, 124, 22082-22095. [CrossRef]

78. Gurinov, A.A.; Denisov, G.S.; Borissova, A.O.; Goloveshkin, A.S.; Greindl, J.; Limbach, H.-H.; Shenderovich, I.G. NMR Study of Solvation Effect on the Geometry of Proton-Bound Homodimers of Increasing Size. J. Phys. Chem. A 2017, 121, 8697-8705. [CrossRef] [PubMed]

79. Limbach, H.-H.; Pietrzak, M.; Sharif, S.; Tolstoy, P.M.; Shenderovich, I.G.; Smirnov, S.N.; Golubev, N.S.; Denisov, G.S. NMRParameters and Geometries of OHN- and ODN Hydrogen Bonds of Pyridine-Acid Complexes. Chem. Eur. J. 2004, 10, 5195-5204. [CrossRef] [PubMed]

80. Lesnichin, S.B.; Tolstoy, P.M.; Limbach, H.-H.; Shenderovich, I.G. Counteranion-Dependent Mechanisms of Intramolecular Proton Transfer in Aprotic Solution. Phys. Chem. Chem. Phys. 2010, 12, 10373-10379. [CrossRef]

81. Chan-Huot, M.; Dos, A.; Zander, R.; Sharif, S.; Tolstoy, P.M.; Compton, S.; Fogle, E.; Toney, M.D.; Shenderovich, I.; Denisov, G.S.; et al. NMR Studies of Protonation and Hydrogen Bond States of Internal Aldimines of Pyridoxal 5'-Phosphate Acid-Base in Alanine Racemase, Aspartate Aminotransferase, and Poly-L-lysine. J. Am. Chem. Soc. 2013, 135, 18160-18175. [CrossRef]

82. Limbach, H.-H.; Chan-Huot, M.; Sharif, S.; Tolstoy, P.M.; Shenderovich, I.G.; Denisov, G.S. Critical Hydrogen Bonds and Protonation States of Pyridoxal 5'-phosphate Revealed by NMR. Biochim. Biophys. Acta (BBA) Proteins Proteom. 2011, 1814, 1426-1437. [CrossRef]

83. Ip, B.C.K.; Shenderovich, I.G.; Tolstoy, P.M.; Frydel, J.; Denisov, G.S.; Buntkowsky, G.; Limbach, H.-H. NMR Studies of Solid Pentachlorophenol-4-Methylpyridine Complexes Exhibiting Strong OHN Hydrogen Bonds: Geometric H/D Isotope Effects and Hydrogen Bond Coupling Cause Isotopic Polymorphism. J. Phys. Chem. A 2012, 116, 11370-11387. [CrossRef]

84. Bismarck, A.; Aranberri-Askargorta, I.; Springer, J.; Lampke, T.; Wielage, B.; Stamboulis, A.; Shenderovich, I.; Limbach, H.-H. Surface Characterization of Flax, Hemp and Cellulose Fibers; Surface Properties and the Water Uptake Behavior. Polym. Compos. 2002, 23, 872-894. [CrossRef]

85. Gurinov, A.A.; Rozhkova, Y.A.; Zukal, A.; Čejka, J.; Shenderovich, I.G. Mutable Lewis and Brønsted Acidity of Aluminated SBA-15 as Revealed by NMR of Adsorbed Pyridine- ${ }^{15}$ N. Langmuir 2011, 27, 12115-12123. [CrossRef]

86. Akcakayiran, D.; Mauder, D.; Hess, C.; Sievers, T.K.; Kurth, D.G.; Shenderovich, I.; Limbach, H.-H.; Findenegg, G.H. Carboxylic Acid-Doped SBA-15 Silica as a Host for Metallo-supramolecular Coordination Polymers. J. Phys. Chem. B 2008, 112, 14637-14647. [CrossRef] [PubMed]

87. Gurinov, A.A.; Mauder, D.; Akcakayiran, D.; Findenegg, G.H.; Shenderovich, I.G. Does Water Affect the Acidity of Surfaces? The Proton-Donating Ability of Silanol and Carboxylic Acid Groups at Mesoporous Silica. ChemPhysChem 2012, 13, $2282-2285$. [CrossRef] [PubMed]

88. Sharif, S.; Shenderovich, I.G.; González, L.; Denisov, G.S.; Silverman, D.N.; Limbach, H.-H. NMR and Ab initio Studies of Small Complexes Formed between Water and Pyridine Derivatives in Solid and Liquid Phase. J. Phys. Chem. A 2007, 111, 6084-6093. [CrossRef] [PubMed]

89. Mauder, D.; Akcakayiran, D.; Lesnichin, S.B.; Findenegg, G.H.; Shenderovich, I.G. Acidity of Sulfonic and Phosphonic AcidFunctionalized SBA-15 under Almost Water-Free Conditions. J. Phys. Chem. C 2009, 113, 19185-19192. [CrossRef]

90. Mulloyarova, V.V.; Ustimchuk, D.O.; Filarowski, A.; Tolstoy, P.M. H/D Isotope Effects on ${ }^{1}$ H-NMR Chemical Shifts in Cyclic Heterodimers and Heterotrimers of Phosphinic and Phosphoric Acids. Molecules 2020, 25, 1907. [CrossRef]

91. Mulloyarova, V.V.; Giba, I.S.; Kostin, M.A.; Denisov, G.S.; Shenderovich, I.G.; Tolstoy, P.M. Cyclic Trimers of Phosphinic Acids in Polar Aprotic Solvent: Symmetry, Chirality and H/D Isotope Effects on NMR Chemical Shifts. Phys. Chem. Chem. Phys. 2018, 20, 4901-4910. [CrossRef]

92. Machida, S.; Sohmiya, M.; Ide, Y.; Sugahara, Y. Solid-State ${ }^{31} \mathrm{P}$ Nuclear Magnetic Resonance Study of Interlayer Hydroxide Surfaces of Kaolinite Probed with an Interlayer Triethylphosphine Oxide Monolayer. Langmuir 2018, 34, 12694-12701. [CrossRef] [PubMed]

93. Seitz, A.E.; Hippauf, F.; Kremer, W.; Kaskel, S.; Scheer, M. Facile storage and release of white phosphorus and yellow arsenic. Nat. Commun. 2018, 9, 361. [CrossRef]

94. Begimova, G.U.; Tupikina, E.Y.; Yu, V.K.; Denisov, G.S.; Bodensteiner, M.; Shenderovich, I.G. Effect of Hydrogen Bonding to Water on the ${ }^{31} \mathrm{P}$ Chemical Shift Tensor of Phenyl- and Trialkylphosphine Oxides and a-Amino Phosphonates. J. Phys. Chem. C 2016, 120, 8717-8729. [CrossRef] 
95. Moussa, M.E.; Shelyganov, P.A.; Wegley, B.; Seidl, M.; Scheer, M. The Potential of the Diphosphorus Complex $\left[\mathrm{C} \mathrm{p}_{2} \mathrm{~W}_{2}(\mathrm{CO}) \mathrm{C}_{4}(\right.$ $\left.\eta^{2}-\mathrm{P}_{2}\right)$ ] as an Organometallic Connecter in Supramolecular Chemistry. Eur. J. Inorg. Chem. 2019, 2019, 4241-4248. [CrossRef] [PubMed]

96. Guenther, J.; Reibenspies, J.; Blümel, J. Synthesis and characterization of tridentate phosphine ligands incorporating long methylene chains and ethoxysilane groups for immobilizing molecular rhodium catalysts. Mol. Catal. 2019, 479, 110629. [CrossRef]

97. Cluff, K.J.; Bhuvanesh, N.; Blümel, J. Monometallic Ni-0 and Heterobimetallic Ni-0/Au-I Complexes of Tripodal Phosphine Ligands: Characterization in Solution and in the Solid State and Catalysis. Chem. Eur. J. 2015, 21, 10138-10148. [CrossRef] [PubMed]

98. Pazderski, L. ${ }^{15} \mathrm{~N}$ and ${ }^{31} \mathrm{P}$ NMR Coordination Shifts in Transition Metal Complexes with Nitrogen- and Phosphorus-Containing Heterocycles. Annu. Rep. NMR Spectrosc. 2013, 80, 33-179. [CrossRef]

99. Hubbard, P.J.; Benzie, J.W.; Bakhmutov, V.I.; Blümel, J. Disentangling Different Modes of Mobility of Triphenylphosphine Oxide Adsorbed on Alumina. J. Chem. Phys. 2020, 152, 054718. [CrossRef]

100. Kharel, S.; Cluff, K.J.; Bhuvanesh, N.; Gladysz, J.A.; Blümel, J. Structures and Dynamics of Secondary and Tertiary Alkylphosphine Oxides Adsorbed on Silica. Chem. Asian J. 2019, 14, 2704-2711. [CrossRef]

101. Hilliard, C.R.; Kharel, S.; Cluff, K.; Bhuvanesh, N.; Gladysz, J.; Bluemel, J. Structures and Unexpected Dynamic Properties of Phosphine Oxides Adsorbed on Silica Surfaces. Chem. Eur. J. 2014, 20, 17292-17295. [CrossRef]

102. Shenderovich, I.G. For Whom a Puddle Is the Sea? Adsorption of Organic Guests on Hydrated MCM-41 Silica. Langmuir 2020, 36, 11383-11392. [CrossRef]

103. Pires, E.; Fraile, J.M. Study of interactions between Brønsted acids and triethylphosphine oxide in solution by ${ }^{31}$ P NMR: Evidence for 2:1 species. Phys. Chem. Chem. Phys. 2020, 22, 24351-24358. [CrossRef]

104. Ostras', A.S.; Ivanov, D.M.; Novikov, A.S.; Tolstoy, P.M. Phosphine Oxides as Spectroscopic Halogen Bond Descriptors: IR and NMR Correlations with Interatomic Distances and Complexation Energy. Molecules 2020, 25, 1406. [CrossRef]

105. Tupikina, E.Y.; Bodensteiner, M.; Tolstoy, P.M.; Denisov, G.S.; Shenderovich, I.G. P=O Moiety as an Ambidextrous Hydrogen Bond Acceptor. J. Phys. Chem. C 2018, 122, 1711-1720. [CrossRef]

106. Arp, F.F.; Bhuvanesh, N.; Blümel, J. Hydrogen peroxide adducts of triarylphosphine oxides. Dalton Trans. 2019, 48, 14312-14325. [CrossRef] [PubMed]

107. Ahn, S.H.; Lindhardt, D.; Bhuvanesh, N.; Blümel, J. Di(hydroperoxy)cycloalkanes Stabilized via Hydrogen Bonding by Phosphine Oxides: Safe and Efficient Baeyer-Villiger Oxidants. ACS Sustainable Chem. Eng. 2018, 6, 6829-6840. [CrossRef]

108. Chernyshov, I.Y.; Vener, M.V.; Shenderovich, I.G. Local-structure effects on ${ }^{31} \mathrm{P}$ NMR chemical shift tensors in solid state. J. Chem. Phys. 2019, 150, 144706. [CrossRef] [PubMed]

109. Golubev, N.S.; Melikova, S.M.; Shchepkin, D.N.; Shenderovich, I.G.; Tolstoy, P.M.; Denisov, G.S. Interpretation of H/D Isotope Effects on NMR Chemical Shifts of [FHF] $]^{-}$Ion Based on Calculations of Nuclear Magnetic Shielding Tensor Surface. Z. Phys. Chem. 2003, 217, 1549-1563. [CrossRef]

110. Fisher, K.J.; Alyea, E.C.; Shehnazarian, N. A ${ }^{31}$ P NMR Study of the Water Soluble Derivatives of 1,3,5-triaza-7-phosphaadamantane (PTA). Phosphorus Sulfur Silicon 1990, 48, 37-40. [CrossRef]

111. Phillips, A.D.; Gonsalvi, L.; Romerosa, A.; Vizza, F.; Peruzzini, M. Coordination chemistry of 1,3,5-triaza-7-phosphaadamantane (PTA) Transition metal complexes and related catalytic, medicinal and photoluminescent applications. Coord. Chem. Rev. 2004, 248, 955-993. [CrossRef]

112. Alyea, E.C.; Fisher, K.J.; Johnson, S. Synthesis, solid state ${ }^{31}$ P CP-MAS NMR, infrared and Raman studies of mercury(II) complexes of 1,3,5-triaza-7-phosphaadamantane (PTA). Can. J. Chem. 1989, 67, 1319-1323. [CrossRef]

113. Smoleński, P.; Kirillov, A.M.; Guedes da Silva, M.F.C.; Pombeiro, A.J.L. Transformations of the Vaska-type complex trans$\left[\mathrm{RhCl}(\mathrm{CO})(\mathrm{PTA})_{2}\right](\mathrm{PTA}=1,3,5$-triaza-7-phosphaadamantane) during stepwise addition of $\mathrm{HCl}$ : Synthesis, characterization and crystal structure of trans-[RhCl 2 (PTA)(PTAH)]. Inorg. Chim. Acta 2011, 378, 342-346. [CrossRef]

114. Kirillov, A.M.; Smoleński, P.; Guedes da Silva, M.F.C.; Pombeiro, A.J.L. The First Copper Complexes Bearing the 1,3,5-Triaza-7phosphaadamantane (PTA) Ligand. Eur. J. Inorg. Chem. 2007, 2007, 2686-2692. [CrossRef]

115. Pellei, M.; Alidori, S.; Camalli, M.; Campi, G.; Lobbia, G.G.; Mancini, M.; Papini, G.; Spagna, R.; Santini, C. Copper(I)organophosphine complexes of bis(3,5-dimethylpyrazol-1-yl)dithioacetate ligand. Inorg. Chim. Acta 2008, 361, $1456-1462$. [CrossRef]

116. Gavara, R.; Pinto, A.; Donamaria, R.; Olmos, M.E.; de Luzuriaga, J.M.L.; Rodriguez, L. Polarized Supramolecular Aggregates Based on Luminescent Perhalogenated Gold Derivatives. Inorg. Chem. 2017, 56, 11946-11955. [CrossRef]

117. Bertrand, B.; Spreckelmeyer, S.; Bodio, E.; Cocco, F.; Picquet, M.; Richard, P.; Le Gendre, P.; Orvig, C.; Cinellu, M.A.; Casini, A. Exploring the potential of gold (III) cyclometallated compounds as cytotoxic agents: Variations on the $\mathrm{C}^{\wedge} \mathrm{N}$ theme. Dalton Trans. 2015, 44, 11911-11918. [CrossRef] [PubMed]

118. Shenderovich, I.G. 1,3,5-Triaza-7-Phosphaadamantane (PTA) as a ${ }^{31}$ P NMR Probe for Organometallic Transition Metal Complexes in Solution. Molecules 2021, 26, 1390. [CrossRef]

119. Straasø, L.A.; Saleem, Q.; Hansen, M.R. A Toolbox of Solid-State NMR Experiments for the Characterization of Soft Organic Nanomaterials. Annu. Rep. NMR Spectrosc. 2016, 88, 307-383. [CrossRef] 
120. Jeziorna, A.; Kazmierski, S.; Paluch, P.; Skorupska, E.; Potrzebowski, M.J. Recent Progress in the Solid-State NMR Studies of Short Peptides: Techniques, Structure and Dynamics. Annu. Rep. NMR Spectrosc. 2014, 83, 67-143. [CrossRef]

121. Jaeger, M.; Aspers, R.L.E.G. Covariance NMR and Small Molecule Applications. Annu. Rep. NMR Spectrosc. 2014, 83, 271-349. [CrossRef]

122. Web of Science. Available online: www.webofknowledge.com (accessed on 31 March 2021). 